Alma Mater Studiorum - Università di Bologna DEPARTMENT OF ECONOMICS

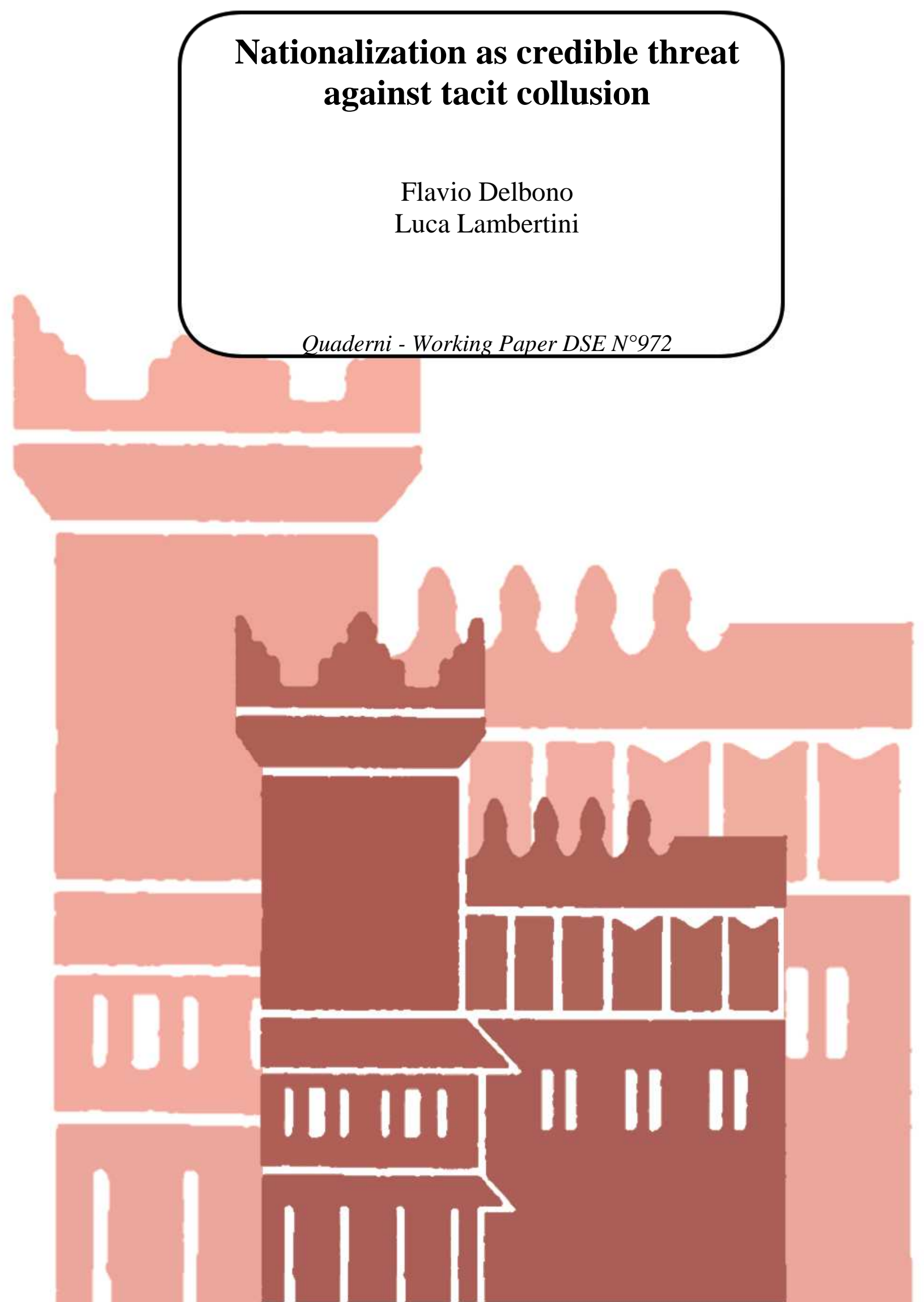




\title{
Nationalization as credible threat against tacit collusion*
}

\author{
Flavio Delbono $\#$ and Luca Lambertini ${ }^{\S}$ \\ \# Department of Economics, University of Bologna \\ Piazza Scaravilli 2, 40126 Bologna, Italy; flavio.delbono@unibo.it \\ $\S$ Corresponding author, Department of Economics, University of Bologna \\ Strada Maggiore 45, 40125 Bologna, Italy; luca.lambertini@unibo.it
}

October 22, 2014

\begin{abstract}
Within a simple model of differentiated oligopoly, we show that tacit collusion may be prevented by the threat of nationalising a private firm coupled with the appropriate choice of the weight given to private profits in the maximand of the nationalised company. We characterise the properties of such a threat and prove that it may allow to credibly deter tacit collusion.
\end{abstract}

Keywords: tacit collusion, nationalization; mixed oligopoly

JEL Codes: H13, L13, L32

*We thank Gianni De Fraja for useful comments. The usual disclaimer applies. 


\section{Introduction}

The view that the public firm is one of the instruments to correct market failures and to improve social welfare is well established. ${ }^{1}$ The presence of market failures like those associated to imperfect or distorted competition may clearly motivate some form of public intervention as, for instance, the creation of a mixed oligopoly. This outcome may be achieved by the policy maker either by creating a new (publicly owned ${ }^{2}$ ) company or by nationalising a private one. The market structure emerging from such operation can then be viewed as intermediate between the extreme situations of "complete government ownership and control, and private ownership restricted by close government supervision in the form of regulation and anti-trust laws" (Merrill and Schneider, 1966, p. 400).

While we share the above view about the ability of public firms in correcting market failures, in this paper we focus on the capacity of nationalization in preventing the important instance of market failure represented by collusion. More precisely, we shall show that the threat of nationalization may discipline oligopolistic firms by forcing them not to collude, not even tacitly. Our paper aims then at filling a gap in the by now large literature on mixed oligopolies. To the best of our knowledge, indeed, such a literature deals with the role of a public firm in altering the equilibrium of an otherwise fully profit-oriented oligopoly. Under different specifications of the oligopolistic game, this debate has improved our understanding of how the policy maker may undertake welfare-improving strategies, for instance by nationalising or privatising firms in an industry. ${ }^{3}$ However, we believe that the public au-

\footnotetext{
${ }^{1}$ See, for instance, the influential textbook by Stiglitz (1987, pp. 156-7).

${ }^{2}$ We use the term 'owned' to identify the agent who takes the relevant decisions.

${ }^{3}$ After the pioneering paper by Merrill and Schneider (1966), the literature started growing in the '80s: for instance, Harris and Wiens (1980), De Fraja and Delbono (1987, 1989) and Cremer, Marchand and Thisse $(1989,1991)$. See De Fraja and Delbono (1990)
} 
thority may successfully enhance social welfare without playing directly as a producer inside the market, but simply by (credibly) threatening of doing it.

Within a model of differentiated oligopoly, we actually show that collusion may be deterred by the threat of nationalising a private company and the appropriate choice of the weight given to private profit in the nationalised firm's objective function. We characterise the relevant features of such a threat and show that it may be able to credibly deter collusion among private firms.

The remainder of the paper is organised as follows. Section 2 presents the model. Section 3 illustrates the different scenarios emerging under competitive or collusive behaviour. The strategy of the policy maker to prevent collusion is presented in section 4 , whereas the consequences of the nationalization threat on private and public incentives are examined in section 5 . Section 6 concludes.

\section{The model}

Consider a Cournot market for a differentiated good, served by $\mathcal{N}=1,2, \ldots, n$ fully symmetric single-product firms, all endowed with the same technology. The demand side is borrowed from Singh and Vives (1984), whereby market demand for variety $i$ is

$$
p_{i}=a-q_{i}-s \sum_{j \neq i} q_{j}
$$

where $p_{i}$ and $q_{i}$ are, respectively, price and quantity of variety $i, a>0$ is the reservation price, and $s \in[0,1]$ measures the degree of substitutability between any two varieties. If $s=1$, the good is homogeneous, if instead $s=0$

for a survey of the early papers and De Fraja (2009) for a more recent account. Excellent books on these themes are Vickers and Jarrow (1988) and Bös (1991). Public firms may also represent an instrument to correct environmental externalities (see Dragone et al., 2014). 
each firm is a monopolist in an isolated market. Parameter $s$ is therefore an inverse measure of the degree of product differentiation. Technology is summarised by the cost function $C_{i}=c q_{i}$, with $c \geq 0$. For the sake of simplicity, and without further loss of generality, we normalise $c$ to zero. As a result, the profit function of firm $i$ writes $\pi_{i}=p_{i} q_{i}$.

The demand system (1) is generated by the following preference structure of the representative consumer:

$$
U=a \sum_{i=1}^{n} q_{i}-\frac{\sum_{i=1}^{n} q_{i}^{2}+2 s \sum_{j \neq i} q_{i} q_{j}}{2}
$$

Hence, consumer surplus is

$$
C S=U-\sum_{i=1}^{n} p_{i} q_{i}
$$

If firms perceive an infinite horizon ahead, and are not completely myopic, ${ }^{4}$ the folk theorem reminds us that they may implement some degree of tacit collusion. Since the supergame is noncooperative, the policy maker would be unable to prevent collusion or to sanction it through standard antitrust instruments. However, we are about to show that there is a strategy allowing the policy maker to deter collusion. The instrument by means of which the policy maker can do so is the threat of nationalising a single profitseeker and assigning it an objective function which is written as follows:

$$
S W=C S+\pi_{P}+b \sum_{i \neq P} \pi_{i}
$$

where $\pi_{P}$ is the profit obtained the publicly owned enterprise in the postnationalisation mixed oligopoly (subscript $P$ stands for public), and $b>0$

\footnotetext{
${ }^{4}$ This amounts to saying that, if firms' time preferences are measured by a discount factor $\delta \in[0,1]$, constant over time and common to all firms, the infinitely repeated game generates infinitely many equilibria characterised by some degree of collusion for any positive $\delta$.
} 
measures the weight assigned to private profits by the policy maker. ${ }^{5}$ Expression (4) is nothing but a standard social welfare function defined in partial equilibrium, where public and private profits are weighted differently whenever $b \neq 1$.

\section{Alternative scenarios}

We now illustrate the ex ante and ex post scenarios emerging in the two alternative perspectives in which private firm either play noncooperatively à la Cournot-Nash or collude. In the latter case, we will focus on full collusion, i.e., the case in which private firms locate along the frontier of industry profits. Irrespective of the behaviour of private firms, in the ex post scenario generated by nationalisation we shall assume that the public firm plays along its best reply function to maximise (4).

\subsection{The ex ante Cournot oligopoly}

The ex ante Cournot-Nash individual profits of the $n$ private firms are

$$
\pi^{N}(n)=\frac{a^{2}}{[2+s(n-1)]^{2}}
$$

where superscript $N$ mnemonics for Nash equilibrium.

If instead firms collude and split evenly the monopoly profits, each of them gets

$$
\pi^{M}(n)=\frac{a^{2}}{4[1+s(n-1)]}
$$

\footnotetext{
${ }^{5}$ Notice that (4) ignores the expenditure involved by the acquisition of one of the $n$ private firms by the policy maker and the corresponding revenue accruing to the private seller of such a firm. This is because the two term cancel each other in the social welfare function.
} 
where $M$ mnemonics for monopoly. The corresponding social welfare is

$$
S W^{M}(n)=n \pi^{M}(n)+C S^{M}(n)=\frac{a[2-n+a(2 n-1)]}{4[1+s(n-1)]}
$$

\subsection{The ex post mixed oligopoly}

We now calculate the Nash equilibrium emerging in the industry if one private firm has been nationalised. The first order condition (FOC) of the generic $i$-th private firm is:

$$
\frac{\partial \pi_{i}}{\partial q_{i}}=a-2 q_{i}-s\left(q_{P}+\sum_{j \neq i} q_{j}\right)=0
$$

while the FOC of the public firm is ${ }^{6}$

$$
\frac{\partial S W}{\partial q_{P}}=a-q_{P}-b s \sum_{i=1}^{n-1} q_{i}+s \sum_{j \neq i} q_{j}=0
$$

Imposing symmetry upon the output levels of all private firms, we can solve the system (8-9) to get the equilibrium output levels:

$$
\begin{aligned}
& q_{P}^{N}(n-1)=\frac{a[2-s(2(2-n)+b(n-1))]}{s^{2}[n-2-b(n-1)]+s(n-2)+2} \\
& q_{\pi}^{N}(n-1)=\frac{a(1-s)}{s^{2}[n-2-b(n-1)]+s(n-2)+2}
\end{aligned}
$$

where subscript $\pi$ mnemonics for profit-seeking. To begin with, let's notice the following property:

Lemma 1 If $b=s=1$, then $q_{P}^{N}(n-1)=a$ and $q_{\pi}^{N}(n-1)=0$.

\footnotetext{
${ }^{6}$ The public firm's reaction function may slope upward (see Delbono and Scarpa, 1995). However, we will focus on parameter constellations in which it is downward sloping.
} 
This is the familiar conclusion emerging in a mixed oligopoly with product homogeneity and constant marginal cost. ${ }^{7}$ As in our model $b$ and $s$ are not, in general, equal to one, we need to establish the parametric conditions under which all output levels are positive in the Cournot-Nash equilibrium of the mixed oligopoly.

Lemma $2 q_{P}^{N}(n-1)$ and $q_{\pi}^{N}(n-1)$ are strictly positive for all $b \in(0, \widehat{b})$, where

$$
\widehat{b}=\frac{2[1+s(n-2)]}{s(n-1)} .
$$

Proof. Output levels (10-11) are both positive iff $b \in(0, \min \{\widehat{b}, \bar{b}\})$, where

$$
\widehat{b}=\frac{2[1+s(n-2)]}{s(n-1)}
$$

and

$$
\bar{b}=\frac{2+s(n-2)(1+s)}{s^{2}(n-1)}
$$

with $\bar{b}>\widehat{b}>0$ for all $s \in(0,1)$.

Notice that $\widehat{b} \geq 2$ for any admissible values of $\{n, s\}$. Therefore, since $b \in(0, \widehat{b})$, outputs $q_{P}^{N}(n-1)$ and $q_{\pi}^{N}(n-1)$ are indeed strictly positive also in the standard formulation of the social welfare function in which $b=1$.

The resulting profits are

$$
\pi_{P}^{N}(n-1)=\frac{a^{2}[3+b(n-1)-2 n][2-s(2(2-n)+b(n-1))] s(1-s)}{\left[2+s(n-2)+s^{2}(n-b(n-1)-2)\right]^{2}}
$$

for the public firm, and

$$
\pi_{\pi}^{N}(n-1)=\frac{a^{2}(1-s)^{2}}{\left[2+s(n-2)+s^{2}(n-b(n-1)-2)\right]^{2}}
$$

\footnotetext{
${ }^{7}$ See De Fraja and Delbono (1987).
} 
for each of the $n-1$ private firms. Using (10-11), one can easily compute consumer surplus $C S^{N}(n-1)$ and social welfare $S W^{N}(n-1)$.

What if, instead, the $n-1$ private firms operating in the mixed oligopoly envisage the possibility of setting up full collusion among themselves? In such a case, we have to characterise the Nash equilibrium between the cartel consisting of the entire population of $n-1$ profit-seeking firms setting their output levels to maximise joint profits

$$
\Pi_{\pi}^{C}(n-1)=\sum_{i=1}^{n-1} \pi_{i}
$$

and the single public firm setting $q_{P}$ to maximise (4). The relevant FOCs are

$$
\frac{\partial \Pi_{\pi}^{C}(n-1)}{\partial q_{i}}=a-2 q_{i}-s\left(q_{P}-2 \sum_{j \neq i} q_{j}\right)=0
$$

for the cartel members, and still (9) for the public enterprise. Relying again on symmetry across profit-seekers, the equilibrium outputs are

$$
\begin{aligned}
& q_{P}^{C}(n-1)=\frac{a[2+s(3(n-2)-b(n-1))]}{s^{2}[n-2-b(n-1)]+2[s(n-2)+1]} \\
& q_{\pi}^{C}(n-1)=\frac{a(1-s)}{s^{2}[n-2-b(n-1)]+2[s(n-2)+1]}
\end{aligned}
$$

The resulting profits per cartel member would be

$$
\pi_{\pi}^{C}(n-1)=\frac{a^{2}(1-s)^{2}[1+s(n-2)]}{\left[2(1+s(n-2))-(2-b+b(n-1)) s^{2}\right]^{2}}
$$

We disregard the non-negativity analysis of $q_{\pi}^{C}(n-1)$ for we are about to show that the policy maker finds it optimal to set $b$ in such a way that, ex post, private firms will not play collusively. 


\section{The policy maker's strategy against collu- sion}

In this section, we show how the policy maker can deter tacit collusion among the population of private firms. The appropriate policy consists in fine tuning the instrument $b$ (the weight given to private profits in the maximand (4) of the public enterprise resulting from nationalization). In other words, the strategy amounts to (i) announcing the nationalization of a single firm out of the initial $n$ private ones, and (ii) adopting maximand (4) by the nationalised company.

Lemma 3 Let $a>0$ and $s \in[0,1] . \pi_{\pi}^{C}(n-1)<\pi_{\pi}^{N}(n-1)$ for all $b \in$ $\left(b_{-}, b_{+}\right)$.

Proof. The solutions of $\pi_{\pi}^{C}(n-1)=\pi_{\pi}^{N}(n-1)$ w.r.t. $b$ are

$$
b_{ \pm}=\frac{1+s(1+s)(n-2) \pm \sqrt{1+s(n-2)}}{(n-1) s^{2}}
$$

Moreover, it can be easily checked that $\pi_{\pi}^{C}(n-1)-\pi_{\pi}^{N}(n-1)$ is convex in $b$, which implies that $\pi_{\pi}^{C}(n-1)<\pi_{\pi}^{N}(n-1)$ for all $b \in\left(b_{-}, b_{+}\right)$.

Hence, in this range, from the private firms standpoint, the game following the nationalization is no longer a prisoners' dilemma.

Proposition 4 Let $a>0$ and $s \in[0,1]$. For all

$$
n \in\left[2, \frac{2 s[5+2 s(s-3)]-1+\sqrt{1+4 s(1-s)}}{2 s(1-s)^{2}} \equiv \widetilde{n}\right]
$$

$\widehat{b} \in\left(b_{-}, b_{+}\right)$. Hence, for all $n \in[2, \widetilde{n}]$, in the mixed oligopoly equilibrium, the $n-1$ private firms are active and play noncooperatively. 
Proof. The proof that $b_{+}>\widehat{b}$ is straightforward and therefore omitted. The sign of $\widehat{b}-b_{-}$is the sign of

$$
[2(2-s)-n(1-s)] s-1+\sqrt{1+s(n-2)}
$$

which is positive for all

$$
n<\widetilde{n}=\frac{2 s[5+2 s(s-3)]-1+\sqrt{1+4 s(1-s)}}{2 s(1-s)^{2}}
$$

For all $s \in[0,1], \widetilde{n}>2$. Moreover, $\tilde{n}$ is increasing and convex in $s$, with $\lim _{s \rightarrow 1} \widetilde{n}=\infty$, and $\lim _{s \rightarrow 0} \widetilde{n}=6$ by de l'Hôpital rule. Therefore, in any point $(b, n)$ belonging to the region

$$
\left\{b \in\left(b_{-}, \widehat{b}\right), n \in(2, \widetilde{n})\right\}
$$

in the mixed oligopoly and all quantities, by Lemma 2, are strictly positive and collusion is not profitable.

Notice that, for all $n>\widetilde{n}, b_{-}>\widehat{b}$, and therefore any $b \in\left(b_{-}, b_{+}\right)$trivially eliminates the prisoners' dilemma among private firms because, by Lemma 2 , these are driven out of the market and the industry becomes a public monopoly replicating perfect competition.

The message stemming from Proposition 4 can be summarised as follows. Since product differentiation increases firms' profits, the nationalization of a single firm and the choice of an appropriate weight assigned to private profits in the public firm's maximand, suffice to contrast collusion only if $n$ is low enough. For $s$ arbitrarily low but still positive, the upper bound of $n$ is 6. Conversely, if $s$ is close to one, the threat of nationalization succeeds to contrast collusion for any $n$. For intermediate values of $s$, the nationalization of a single firm does not eliminate the incentive to collude for all $n>\widetilde{n}$. In such a region, we may conjecture that preventing collusion requires the threat of nationalising more than one firm. 
The region $\left\{b \in\left(b_{-}, \widehat{b}\right), n \in(2, \widetilde{n})\right\}$ identified in Proposition 4 is the area below the curve $\widetilde{n}$ represented in Figure 1, drawn in the space $(s, n)$.

Figure 1 The curve $\widetilde{n}$ in the space $(s, n)$.

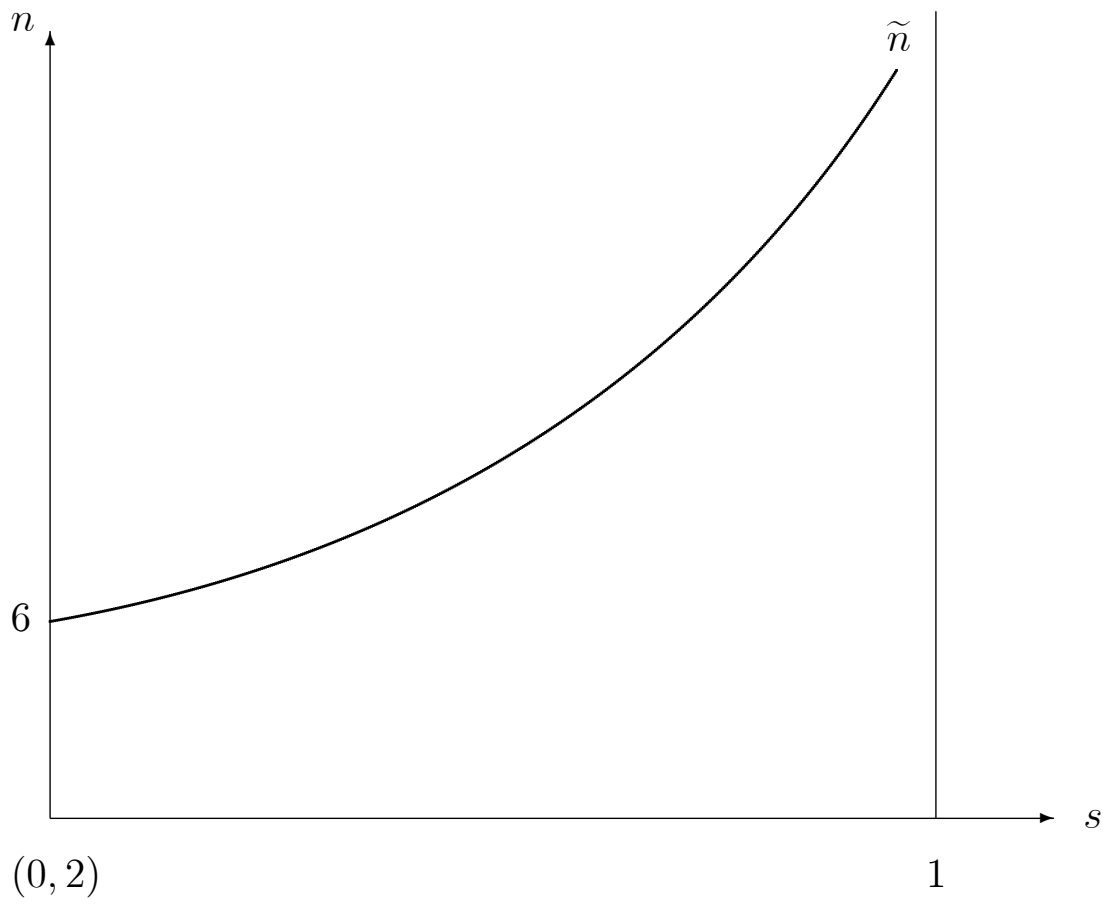

\section{Private and public incentives}

In order to understand the consequences of the nationalization threat on their own profits, private firms compare $\pi_{\pi}^{N}(n)$ and $\pi_{\pi}^{N}(n-1)$ :

$\pi_{\pi}^{N}(n)-\pi_{\pi}^{N}(n-1)=\frac{a^{2}[s(3+b(n-1)-2 n)-1]\left[b(n-1) s^{2}+s^{2}-4-s(2 n-5)\right]}{\left[2+s(n-2)+s^{2}(n-b(n-1)-2)\right]^{2}[2+s(n-1)]^{2}}$ 
the above expression is positive for all $b$ outside the interval:

$$
\left(b_{\pi 1}=\frac{s(2 n-3)+1}{s(n-1)}, b_{\pi 2}=\frac{s(2 n-5)+4-s^{2}}{s^{2}(n-1)}\right)
$$

with $b_{\pi 1}>\widehat{b}$ for all $\{s, n\}$. This establishes:

Proposition $5 \pi_{\pi}^{N}(n)>\pi_{\pi}^{N}(n-1)$ for all $b \in(0, \widehat{b})$.

This means that, facing the threat of nationalization, the ex ante $n$ private firms have a strict incentive to play noncooperatively avoiding thus the danger of finding themselves in a mixed oligopoly where the public firm maximises a social welfare function which yields lower private profits than in the Cournot-Nash equilibrium.

We can summarised the results spelled in Lemma 3 and Propositions 4-5 as follows:

Corollary 6 If $n<\widetilde{n}, \pi_{\pi}^{N}(n)>\pi_{\pi}^{N}(n-1)>\pi_{\pi}^{C}(n-1)$ for all $b \in\left(b_{-}, \widehat{b}\right)$.

Proof. If $n<\widetilde{n}, b_{-}<\widehat{b}$ by Proposition 4; hence, for $b \in\left(b_{-}, \widehat{b}\right)$, we have $\pi_{\pi}^{N}(n)>\pi_{\pi}^{N}(n-1)$ by Proposition 5 and $\pi_{\pi}^{N}(n-1)>\pi_{\pi}^{C}(n-1)$ by Lemma 3.

In words, this means that, when the number of firms is sufficiently small, the policy maker succeeds in inducing private firms to stick to the CournotNash behaviour. Moreover, in a mixed oligopoly, private firms, even if colluding, would get lower profits than in the fully private Cournot-Nash equilibrium.

Now we have to ascertain whether the threat of nationalization is indeed welfare-enhancing. This amounts to checking whether the ex post welfare level is higher than the ex ante welfare level generated by the Cournot-Nash equilibrium among $n$ private firms. However, to do that, it suffices to look at aggregate output in the two scenarios:

$$
Q^{N}(n)=\frac{n a}{2+s(n-1)}
$$




$$
\begin{gathered}
Q^{N}(n-1)=q_{P}^{N}(n-1)+(n-1) q_{\pi}^{N}(n-1)= \\
\frac{a[n+1-s(3+b(n-1)-n)]}{s[n-2-s(2-n+b(n-1))]-2}
\end{gathered}
$$

The sign of $Q^{N}(n)-Q^{N}(n-1)$ is the sign of

$$
\frac{(s-2)[s(3-2 n+b(n-1))-1]}{s[2-n+s(2-n+b(n-1))]-2}
$$

where the numerator is positive for all $b<b_{\pi 1}$, and the denominator is negative for all $b<\bar{b}$. Therefore, since $b<b_{\pi 1}$ and, by Lemma $2, \bar{b}>\widehat{b}$, we know that $Q^{N}(n)<Q^{N}(n-1)$ for all $b<\widehat{b}$, which in turn implies

Proposition $7 S W^{N}(n-1)>S W^{N}(n)$ for all $b \in(0, \widehat{b})$.

The combined reading of Propositions 5 and 7 tells that the threat of nationalization is credible as it would increase welfare. Hence, since under complete information private firms are aware of that, they are forced to play the Cournot-Nash equilibrium ex ante, where they are better off w.r.t. the mixed oligopoly Cournot-Nash equilibrium. By setting $b \in(0, \widehat{b})$ in the maximand of the (threatened) public firm, the policy maker disciplines the $n$ private firms without needing to carry out the threat. Needless to say, for all $b \in(0, \widehat{b}), S W^{N}(n-1)$ is also greater than $S W^{M}(n)$ as given by (7). Hence, by means of the nationalization threat, the policy maker achieves a level of social welfare which is intermediate between $S W^{M}(n)$ and $S W^{N}(n-1)$. Moreover, the policy maker may prevent collusion also in the mixed oligopoly only if $n$ is sufficiently small. In that case, indeed, it will be able to choose a value of $b \in\left(b_{-}, \widehat{b}\right)$, which forces private firms to play nonocooperatively. That is to say, our analysis boils down to the following:

Theorem 8 If $b \in(0, \widehat{b})$, in the mixed oligopoly all $n$ firms are active, $\pi_{\pi}^{N}(n)>\pi_{\pi}^{N}(n-1)$ and $S W^{N}(n-1)>S W^{N}(n)$. The policy maker may prevent collusion among the $n-1$ private firms also in the mixed oligopoly only if $n<\tilde{n}$. 
To illustrate how the threat can be enforced, it is worth noting that the maximum price that the policy maker is prepared to pay to acquire a private firm is given by the cartel profit $\pi^{M}(n)$. However, this would not be the net effect on the policy maker's balance sheet, because the public firm would make positive profits $\pi_{P}^{N}(n-1)$ in the prospected mixed oligopoly equilibrium. At any rate, we may ignore the effects of the acquisition in the social welfare function (see fn. 5).

A threat is credible insofar as it doesn't need to be implemented. Since this is the case within our setting, to credibly commit to the nationalization strategy, the policy maker need only to allocate the difference between $\pi^{M}(n)$ and $\pi_{P}^{N}(n-1)$, being aware that such amount will never be utilised. Hence, the true cost of the commitment is given by the opportunity cost of such an allocation in the balance sheet.

Our formulation of the nationalization threat fits the requirements suggested by Schelling (1960) for a move to represent a credible commitment: visibility, irreversibility and expensiveness. In Schelling's words, indeed: "The first point to observe is that a commitment, a promise or a threat can usually be characterised in a fashion equivalent to the following: to make one of these moves, a player selectively reduces - visibly and irreversibly some of his own payoff in the matrix. This is what the move amounts to." (Schelling, 1960, p. 150, italics in the original)

\section{Concluding remarks}

Our paper develops a first approach to modelling the deterring power of nationalization in preventing collusion. We have shown how the policy maker may prevent tacit collusion in a differentiated oligopoly. The threat of nationalising a private firm, coupled with the appropriate choice of the weight given to private profits in the public firm's maximand, forces private firms 
to escape from collusion.

The simplicity of our model implicitly suggests some extensions: we mention two. The first one amounts to considering multiple nationalization, i.e., the analysis of how many private firms should be expropriated for the threat to be credible in deterring tacit collusion. The second more ambitious extension would entail modelling incomplete information by the policy maker about technology and/or market demand. Both extensions are left for future research. 


\section{References}

[1] Bös, D. (1991), Privatization: A Theoretical Treatment, Oxford, Clarendon Press.

[2] Cremer, H., M. Marchand and J.-F. Thisse (1989), The Public Firm as an Instrument for Regulating an Oligopolistic Market, Oxford Economic Papers, 41, 283-301.

[3] Cremer, H., M. Marchand and J.-F. Thisse (1991), Mixed Oligopoly with Differentiated Products, International Journal of Industrial Organization, 9, 43-53.

[4] De Fraja, G. (2009), Mixed Oligopoly: Old and New, working paper 09/20, Department of Economics, University of Leicester.

[5] De Fraja, G. and F. Delbono (1987), Oligopoly, Public Firm and Welfare Maximization: A Game-theoretic Analysis, Giornale degli Economisti e Annali di Economia, 46, 417-35.

[6] De Fraja, G. and F. Delbono (1989), Alternative Strategies of a Public Enterprise in Oligopoly, Oxford Economic Papers, 41, 302-11.

[7] De Fraja, G. and F. Delbono (1990), Game Theoretic Models of Mixed Oligopoly, Journal of Economic Surveys, 4, 1-17.

[8] Delbono, F. and C. Scarpa (1995), Upward-Sloping Reaction Functions under Quantity Competition in Mixed Oligopolies, Bulletin of Economic Research, 47, p. 341-7.

[9] Dragone, D., L. Lambertini and A. Palestini (2014), Regulating Environmental Externalities through Public Firms: A Differential Game, Strategic Behavior and the Environment, 4, 15-40. 
[10] Harris, H. and E. Wiens (1980), Government Enterprise: An Instrument for the Internal Regulation of Industry, Canadian Journal of Economics, 13, 125-32.

[11] Merrill, W. and N. Schneider (1966), Government Firms in Oligopoly Industries, Quarterly Journal of Economics, 80, 400-12.

[12] Schelling, T. (1960), The Strategy of Conflict, Cambridge, MA, Harvard University Press.

[13] Singh, N. and X. Vives (1984), "Price and Quantity Competition in a Differentiated Duopoly", RAND Journal of Economics, 15, 546-54.

[14] Stiglitz, J. (1987), Public Sector Economics, New York, Norton.

[15] Vickers, J. and G. Yarrow (1988), Privatization: An Economic Analysis, Cambridge, MA, MIT Press. 


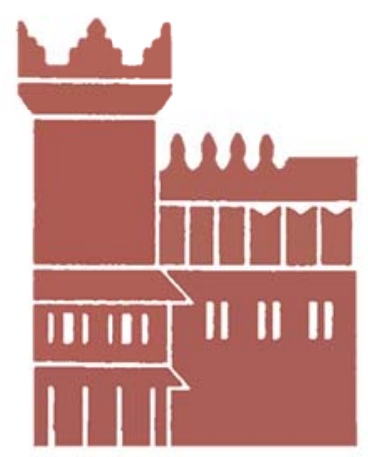

Alma Mater Studiorum - Università di Bologna DEPARTMENT OF ECONOMICS

Strada Maggiore 45

40125 Bologna - Italy

Tel. +39051 2092604

Fax +390512092664

http://www.dse.unibo.it 